\title{
Radiation budget estimates over Africa and surrounding oceans: inter-annual comparisons
}

\author{
A. Ben Rehouma, M. Viollier, and M. Desbois \\ Laboratoire de Météorologie Dynamique, Institut Pierre Simon Laplace, Ecole Polytechnique, 91128 Palaiseau Cedex, France
}

Received: 20 July 2006 - Published in Atmos. Chem. Phys. Discuss.: 13 December 2006

Revised: 8 March 2007 - Accepted: 4 May 2007 - Published: 21 May 2007

\begin{abstract}
Three independent datasets of Radiation Budget at the top of the atmosphere (TOA) spanning two decades are compared: the Scanner Narrow Field of View data (from ERBE, ScaRaB, and CERES instruments, 1985-2005), the ERBS Nonscanner Wide Field of View data (1985-1998) and the simulated broadband fluxes from the International Satellite Cloud Climatology Project (ISCCP-FD, 1983-2004). The analysis concerns the shortwave (SW) reflected flux, the longwave (LW) emitted flux and the net flux at the Top Of the Atmosphere (TOA) over Africa and the surrounding oceans $\left(45^{\circ} \mathrm{S}-45^{\circ} \mathrm{N} / 60^{\circ} \mathrm{W}-60^{\circ} \mathrm{E}\right)$, a region particularly impacted by climate variability. For each month, local anomalies are computed with reference to the average over this large region, and their differences between the 2002-2005 and 1985-1989 periods are analysed. These anomalies are, for a large part, independent on the general observed trends (about $2.5 \mathrm{~W} \mathrm{~m}^{-2}$ per decade), which may be affected by possible calibration drifts. Although the regional flux anomalies can be related to calibration through the scene identification and the choice of the anisotropy correction, this effect is limited if the calibration drifts remains reasonable. Large inter-annual variations are observed locally. Over a part of the South East Atlantic $\left(35^{\circ}-10^{\circ} \mathrm{S} / 10^{\circ} \mathrm{W}-10^{\circ} \mathrm{E}\right)$, including the marine low cloud area off Angola, there is a decrease of the yearly means of net flux estimated to $2.2,3$ and $6 \mathrm{~W} \mathrm{~m}^{-2}$ respectively for the Scanner, Nonscanner and ISCPP-FD data. Over a narrow strip of the Sahel Zone, the net flux increases by about $5 \mathrm{~W} \mathrm{~m}^{-2}$. We believe that these observations are real. They could be due to the impact of calibration drift but only if the drifts were significant ( $>4 \%)$ and correlated between the datasets, which is highly improbable.
\end{abstract}

Correspondence to: A. Ben Rehouma

(asma.ben-rehouma@lmd.polytechnique.fr)

\section{Introduction}

The continuous global observations of the Earth from satellites are becoming fundamental for climate and environment studies. However, compared to the temporal scales used for climate studies, observations of the Earth from space are quite recent and are based on instruments with short lifetimes (a few years). It is therefore difficult to perform interannual comparisons and analyses of the climate variability from space. Large efforts are necessary to ensure successive space missions with compatible instruments and data processing and to generate consistent multi-year dataset. Many studies using these datasets intend to infer global trends in different parameters, as the cloud coverage or the components of the radiative budget of the Earth. This is difficult because the observed variations, due to mixing regions with different behaviours, are very small and remain close to the accuracy of the retrieved products. Regional trends on homogeneous climatic areas are more prone to be detectable, especially in sensible areas as the Sahel, convective zones of the ITCZ, or oceanic regions covered with stratocumulus decks. That is why the present paper concentrates on variations observed over the African-Atlantic area.

One of the best examples of a consistent multi-year data set was derived from the the Earth Radiation Budget Experiment (ERBE; Barkstrom et al., 1989), the Scanner for Radiation Budget (ScaRaB; Kandel et al., 1998) and the five instruments of the Clouds and the Earth's Radiant Energy System (CERES; Wielicki et al., 1996). A second example is the International Satellite Cloud Climatology Project (IS$\mathrm{CCP}$ ) with data collected from geostationary (mainly METEOSAT, GOES and GMS) and polar satellites (NOAA). Both programs provide a large dataset spanning two decades (1985 to 2005).

Time evolutions from these datasets have already been studied by several authors. Looking to the ERBE/CERES series between 1985 and 2000, Wielicki et al. (2002) found an

Published by Copernicus Publications on behalf of the European Geosciences Union. 
increase of the tropical means of the emitted infrared radiation of about $3 \mathrm{~W} \mathrm{~m}^{-2}$. In parallel, they observed a decrease of the SW reflected flux (about $2 \mathrm{~W} \mathrm{~m}^{-2}$ ). These observations were found consistent with the decrease of cloudiness observed with ISCCP data (Chen et al., 2002). The relationships between ISCCP cloud properties and the TOA radiation budgets have also been investigated in many studies (for example Ringer, 1997; Ringer and Shine, 1997; Hatzidimitriou et al., 2004; Robertson et al., 2004). However, the observed LW and SW trends are as large as they cannot be easily simulated by the climate models (Allan and Slingo, 2002). The accuracies of satellite datasets have been strongly debated, and the conclusions are being re-examined. For the ERBS Nonscanner, Wong et al. (2006) found two corrections which almost cancel the LW increase (from 3.1 to $0.7 \mathrm{~W} \mathrm{~m}^{-2}$ ). For ISCCP parameters, Campbell (2004) argues that the addition of new geosynchronous data has gradually changed the residual angular errors which can cancel the decreasing trend in cloud amount, both regionally and globally.

Recently, the ISCCP and CERES data have also been used to estimate the surface fluxes using different techniques (Pinker et al., 2005; Wielicki et al., 1996). With similar or innovative methods, local long series are derived from each geostationary data, for example from Meteosat (Rigollier et al., 2004; EUMETSAT Satellite Application Facility on Climate Monitoring). The data directly measured at surface stations (mainly continental) have also been analysed for studying long-term variability. For example, Wild et al. (2005) conclude to a decline of the solar insolation at the Earth's surface (also called "global dimming") between 1960 and 1990, which may be related to an increase of aerosol content in the atmosphere.

Certainly, all these datasets are not as accurate and homogeneous as required. Differences in the local time of observations as well as in the viewing geometry, and drifts of the radiometric calibration introduce small errors which can easily raise above real variations of the Earth radiation changes. This is specifically the case for the analysis of the global means since the observed variations are close to the uncertainty range (Kandel and Viollier, 2005). The differences for smaller space and time intervals, however, can be more significant. First, they can frequently reach much higher levels. Secondly, regional anomalies are mostly independent of the calibration drifts which mainly impact all the data in the same way as far as the drifts remain reasonable (1-2\%). When the calibration changes become larger, they can modify the scene indentification and then the choice of the flux anisotropic correction (see discussion in Sect. 3.4). With careful studies of the error sources, and comparisons between three independent datasets (Scanners, Nonscanner, and simulated broadband fluxes from ISCCP-FD), this paper points out regional variations of ERB between 1985 and 2005 over Africa and its surroundings.

\section{Data}

We use three independent datasets. The first called 'Scanner dataset' contains data from the ERBE, ScaRaB and CERES instruments of the satellite missions listed in Table 1. The three instruments are different, but all have a scanning mechanism and observe the Earth with a swath of 400 to $2000 \mathrm{~km}$ and instantaneous field of view of 10 to $50 \mathrm{~km}$, depending on the instrument optics and the satellite altitude. There are two main channels: total $(0.2$ to $100 \mu \mathrm{m})$ and SW $(0.2$ to $5 \mu \mathrm{m})$. The day-time LW radiances are determined from the difference between both channels. Onboard calibration systems (blackbodies, tungsten lamp, and solar diffuser plate) and inter-channel consistency tests provide highly accurate radiances. The ERBE and ScaRaB instrument calibration studies estimate the absolute accuracies of the LW and SW radiances respectively to $1 \%$ and $2 \%$ (Barkstrom et al., 1989; Kandel et al., 1998). The accuracies of CERES are 0.5 and $1 \%$ respectively (Wielicki et al., 1996). For CERES, a SW calibration drift of $1.5 \%$ has been detected and seems to have occurred when the instrument operated in rotating scan mode (Matthews et al., 2005). This drift is corrected in our datasets. Furthermore cross-checking between two scanners (Haeffelin et al., 2001) and between Scanner and Non scanner (Smith et al., 2006) have shown differences at the $1 \%$ level. From radiances, fluxes are computed using an angular model, and they are temporally averaged using diurnal models. All the Scanner data are available from ERBE-like algorithms. Note the new generation of CERES SRBAVG monthly means data is recently available to the public with higher monthly means accuracy from improved angular dependence model (Loeb et al., 2005) and better diurnal cycle of radiation using geostationary data (Young et al., 1998), while the GERB mission (Harries et al., 2005) improves the accuracy of daily integrations. The outputs of ERBE-like flux data consist of regional monthly means over a $2.5^{\circ} \times 2.5^{\circ}$ latitude and longitude grid. In that follows, we have used for ERBE the combined monthly means from ERBS, NOAA-9 and NOAA-10, and for CERES the TRMM (ES4, Edition 2) and Terra products (ES4, FM1, Edition 2 Rev1). For the common Aqua-Terra period (July 2002 to December 2005) we have used the average of the two satellite products (FM1 and FM3). For the SW analyses, the Terra alone products (until June 2002) are not taken into account to reduce the impact of diurnal errors, since they correspond to only one morning observation. Despite of differences in the instrument designs and satellite orbits, the Scanner series should be quite homogenous owing to accurate calibration and similar ERBE-like data processing.

The second dataset is the 15-year continuous record of the ERBS WFOV (Wide Field of View) non scanning radiometer (1985-1999). The instrument uses two active cavity hemispheric sensors for measuring the total and SW radiations. Regular solar views allow the evaluation of the stability of the total channel to $0.1 \%$ and the correction for the degradation 
Table 1. Summary of the radiation budget datasets. Column 5 gives the local time of ascending node (LTAN) for sun-synchronous orbits, or the precession period (PP) for slowly drifting orbits.

\begin{tabular}{llllll}
\hline Mission & Satellite & Inclination $\left(^{\circ}\right)$ & Orbit type & LTAN or PP & Period of operation \\
\hline \multirow{2}{*}{ ERBE } & ERBS & 57 & precessing & 72 days & $\begin{array}{l}\text { Non-Scanner Nov 1984-1999 } \\
\text { NoAnner Nov 1984-Feb 1990 } \\
\end{array}$ \\
& NOAA-10 & 99 & Sun-synchronous & $15: 00$ & March 1985-Jan 1987 \\
& NOA & Sun-synchronous & $19: 30$ & Dec 1986-May 1989 \\
\hline \multirow{2}{*}{ ScaRaB } & Meteor-3/7 & 82 & precessing & 209 days & Feb 1994-March 1995 \\
& Resurs-0 & 99 & Sun-synchronous & 22:00 & Nov 1998-March 1999 \\
\hline \multirow{2}{*}{ CERES } & TRMM & 35 & precessing & 50 days & Dec 1997-Sep 1998 \\
& Terra FM1 and 2 & 99 & Sun-synchronous & $22: 30$ & March 2000-... \\
& Aqua FM3 and 4 & 99 & Sun-synchronous & $13: 30$ & July 2002-... \\
\hline
\end{tabular}

of the SW filters. The Non-scanner then is considered as the most reliable instrument, with a radiometric stability estimated to $0.5 \%$ for the SW and day-time LW. Contrary to the scanning radiometers, the field of view is large, from horizon to horizon, with an effective diameter of about $1500 \mathrm{~km}$. The measurements are converted to TOA fluxes (Green and Smith, 1991), temporally averaged over the $72^{\circ}$ precession cycle and ordered over a $10^{\circ}$ grid ("S10" product). With variable observation times due to the ERBS precessing orbit, the temporally averaged fluxes are less sensitive to diurnal sampling errors than those estimated from scanner instruments (most on sun-synchronous orbits). Although considered as the most reliable, these Nonscanner data, however, faced SW calibration drifts and processing issues. They were re-examined several times (Wong et al., 2006). We have used the latest version (Edition 3 Revision 1).

The third dataset consists of simulated broadband flux estimates from the International Satellite Cloud Climatology Project (ISCCP, Rossow and Schiffer, 1991, 1999). The flux products (ISCCP-FD, version ii, Zhang et al., 2004) are computed from broadband radiative transfer code with global information on cloud fields (ISCCP-DX-D1) every three hours from weather satellite data as main input. Other inputs are daily atmospheric profiles of temperature and humidity and climatology of numbers of parameters (cloud vertical layer distributions, cloud particle size, stratospheric water vapour, aerosols, diurnal cycle of near-surface air temperature, spectral dependence of surface albedo and emissivity). Cloud characteristics are retrieved from high resolution data (1$5 \mathrm{~km}$ ) sampled at $30 \mathrm{~km}$ with data collected from passive visible and infrared imaging radiometers on board geostationary (mainly METEOSAT, GOES and GMS) and polar satellites (NOAA). The visible channel calibration uses vicarious calibration. In both spectral ranges, careful inter-comparisons between the different satellite data (Desormeaux et al., 1993; Brest et al., 1997) allow to derive the relative uncertainty (or stability): $3 \%$ in the visible and $1 \%$ in the infrared. The abso- lute uncertainty remains larger. The overall uncertainties of the monthly means of the TOA fluxes result from a complex relation of uncertainties in the satellite analysis and radiation transfer computations. They are estimated to $5-10 \mathrm{~W} \mathrm{~m}^{-2}$. The data record is available since July 1983 to now.

From this short presentation of complex projects, one can realize how the three datasets are independent and complementary. The Scanner series is based on moderate spatial resolution (a few tenths of $\mathrm{km}$ ) and on onboard calibration systems. The data processing uses identical angular and diurnal models. But the records are not continuous due to the short life time of the instruments (a few years). On the contrary, the ERBS active cavity hemispheric sensors have been working continuously from 1985 to 2000 , but they have a coarse spatial resolution $(1000 \mathrm{~km})$ and the data processing uses specific inversion algorithms. The calibration and data processing of the ISCCP-FD flux are quite different since they are based on narrow-band radiances from weather satellites every three hours.

\section{Analysis results}

\subsection{Long term mean values and standard deviations}

From the average of all available Scanner data between 1985 and 2005, the spatial distributions of the LW flux $\left(\mathrm{W} \mathrm{m}^{-2}\right)$ are shown on Figs. 1a and $\mathrm{b}$ for two months: January and August. These months correspond respectively to the winter and summer seasons of the Northern latitudes and to the dry and wet seasons over the Tropical West Africa. In January, over the continent, maxima are located along a zonal band stretching around $15^{\circ} \mathrm{N}$, from Senegal to Sudan, particularly marked to the east of Lake Chad. For the same month, minima occur over South America and South Africa, between $5^{\circ} \mathrm{S}$ and $20^{\circ} \mathrm{S}$ corresponding to deep convective clouds. Over the Atlantic, ITCZ is observed between $0^{\circ}$ and $5^{\circ} \mathrm{N}$. In August, the northern area of the largest LW fluxes 

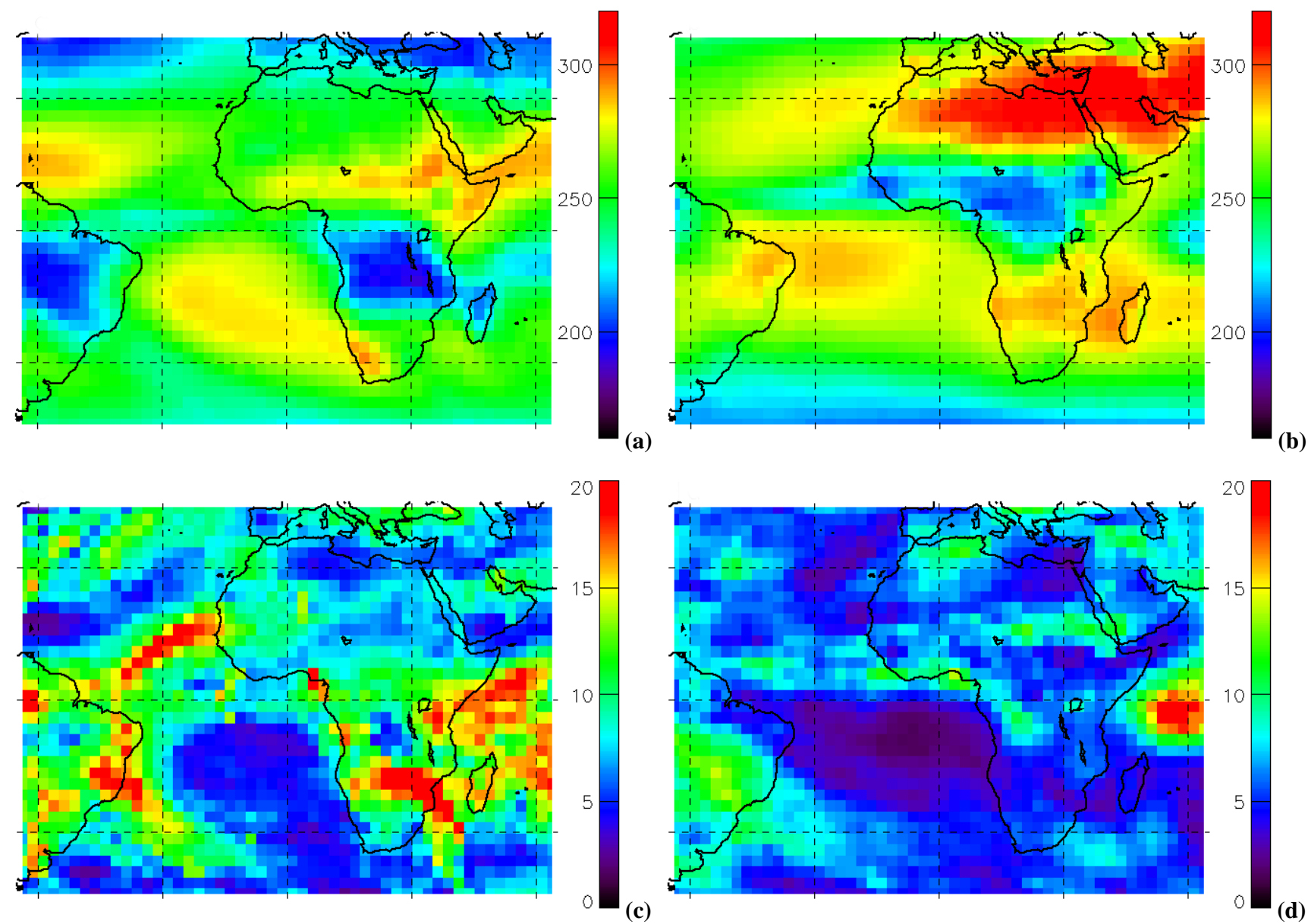

Fig. 1. Means of the LW fluxes $\left(\mathrm{W} \mathrm{m}^{-2}\right)$ over Africa and surrounding oceans for the available Scanner data in January and August (a, b), and corresponding standard deviations $(\mathbf{c}, \mathbf{d})$.

extends over the Sahara and Arabia deserts and the south Mediterranean Sea. The ITCZ is more continuous between ocean and continent than for January and has moved slightly northwards up to $10^{\circ} \mathrm{N}$.

From the same data set, the corresponding standard deviations are presented for the same months (January and August) on Fig. 1c and d as the first step to emphasize the areas of large inter-annual variability. For both months, the standard deviations are relatively lower over the African continent than over other regions, except for January close to the Southern Hemisphere Tropic. In August, the most variable parts of Africa are: Maghreb, Sudan, and South coast of West Africa (Guinean zone). The highest deviations are observed over the Atlantic around the ITCZ and SACZ (the south-east extension of the convective band that originates in the Amazon Basin) and over Indian Ocean. Note that these extreme values are lower than those observed in Pacific Ocean and related to El Niño events (Cess et al., 2001; Allan et al., 2002).
In a broad sense, the maps of SW reflected fluxes (Figs. 2a and b) reveal the same patterns, but with opposite sign, meaning that flux variations are mainly driven by the cloud cover, colder and brighter than the surface. One exception, the marine boundary layer clouds clearly appear over the ocean to the west of Africa, specifically off Angola in August, due to low clouds which are not detected by thermal differences. The SW standard-deviations (Figs. 2c and d) also reveal high variability over these areas. Over the whole area and for both months, the standard deviations are larger than for the LW domain.

\subsection{Statistical differences between datasets}

The maps (not shown) of averages and standard-deviations from the ISCCP-FD fluxes exhibit similar patterns as presented on Figs. 1 and 2 for the Scanner series. This is also true for those of the Nonscanner data, although the patterns are strongly smoothed by the coarse resolution. 

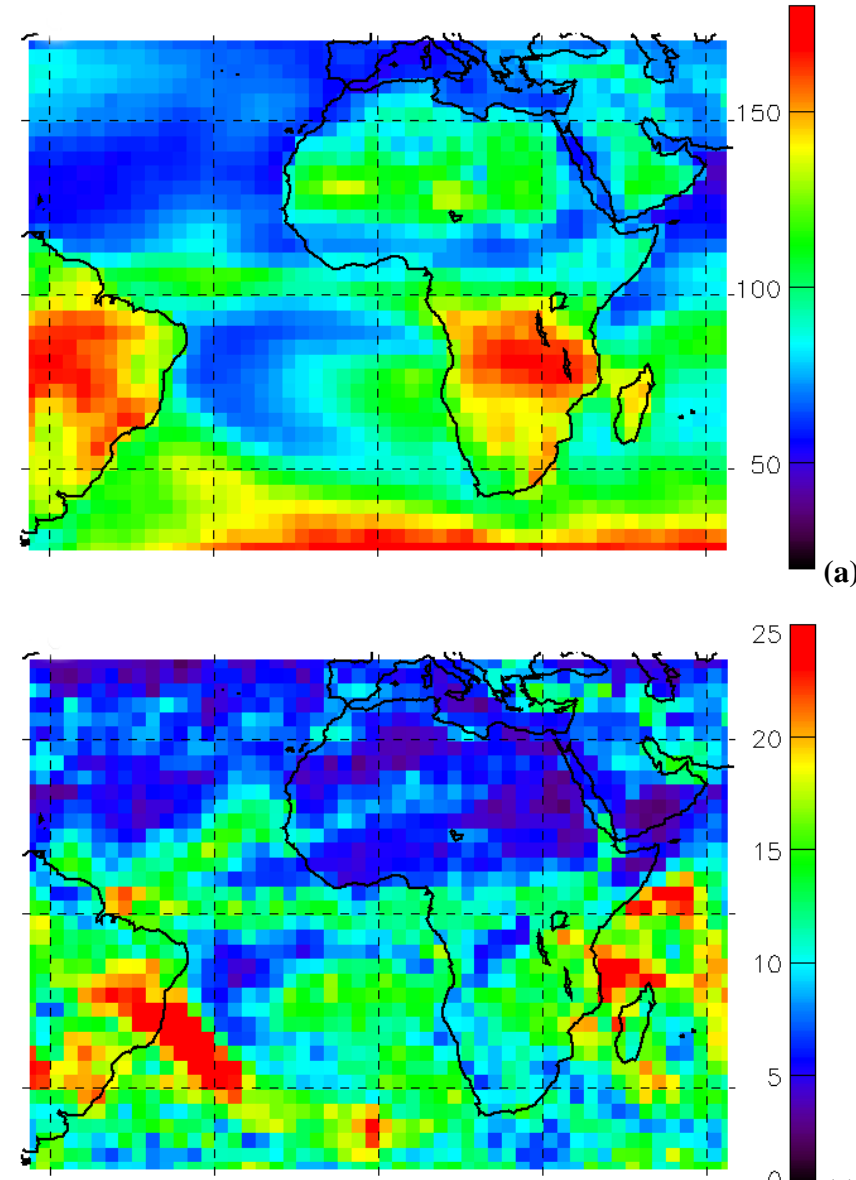
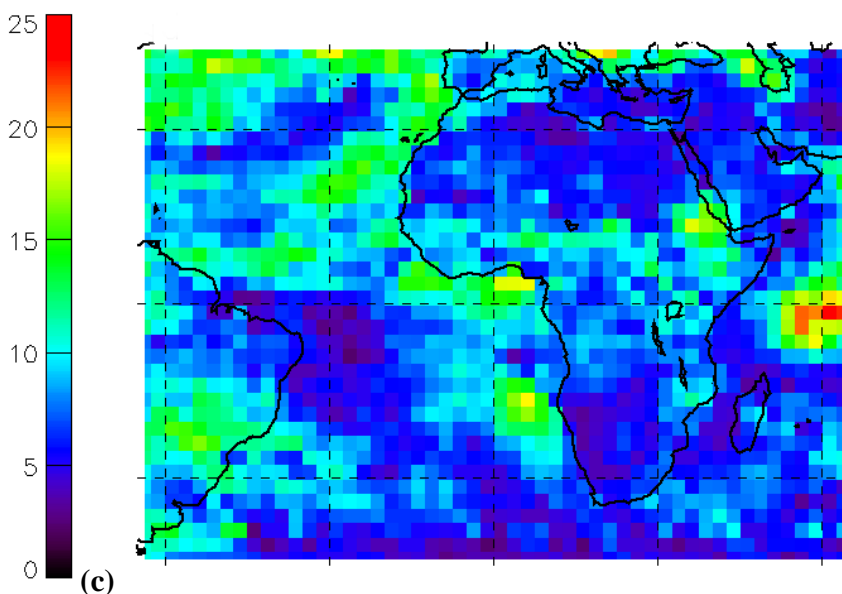

(b)

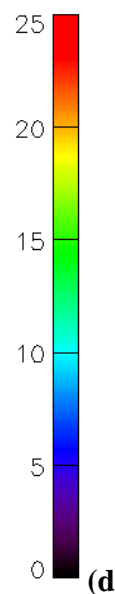

Fig. 2. Same as Fig. 1 but for the SW fluxes.

Quantitatively, each pairs of datasets are highly correlated. The lower correlation $(R=0.70)$ is found for the SW ScannerNonscanner comparisons, and the higher $(R=0.98)$ for the LW Scanner/ISCCP-FD pairs. However, there are significant biases between the three datasets. Table 2 summarizes the mean and rms differences between each pair of datasets for the LW and SW fluxes over the area presented on Fig. 1. Due to gaps in the series, only the common period 1985-1989 is considered. In the LW domain, the largest difference does not rise above $4 \mathrm{~W} \mathrm{~m}^{-2}$ (or $1.5 \%$ ). In the SW domain, differences are more significant: ISCCP-FD fluxes are higher by about $7 \mathrm{~W} \mathrm{~m}^{-2}$ (or $7 \%$ ) compared to Scanner and Nonscanner data. The rms differences between ISCCP and scanner data are rather low $5.8 \mathrm{~W} \mathrm{~m}^{-2}(\mathrm{LW})$ and $9.25 \mathrm{~W} \mathrm{~m}^{-2}(\mathrm{SW})$, but they are larger with the Nonscanner.

\subsection{Time variability}

In this section, we examine temporal flux anomalies of the whole area centred over Africa $\left(45^{\circ} \mathrm{S}-45^{\circ} \mathrm{N} / 60^{\circ} \mathrm{W}-60^{\circ} \mathrm{E}\right)$
Table 2. Mean and rms differences of LW and SW Flux $\left(\mathrm{W} \mathrm{m}^{-2}\right)$ for each pair of datasets over the Africa and surroundings $\left(45^{\circ} \mathrm{S}-\right.$ $45^{\circ} \mathrm{N} / 60^{\circ} \mathrm{W}-60^{\circ} \mathrm{E}$ ) for the common period 1985-1989.

\begin{tabular}{lcccc}
\hline & \multicolumn{2}{c}{ LW } & \multicolumn{2}{c}{ SW } \\
\hline Flux Difference $\left(\mathrm{W} \mathrm{m}^{-2}\right)$ & mean & rms & mean & rms \\
\hline Scanner - Nonscanner & +2.74 & 16.1 & 1.90 & 21.0 \\
Scanner - ISCCP FD & +3.04 & 5.8 & -5.74 & 9.2 \\
ISCCP-FD - Nonscanner & -0.66 & 14.5 & 7.64 & 20.3 \\
\hline
\end{tabular}

represented on Figs. 1 and 2. The monthly anomaly is calculated with reference to a monthly climatology, mean value of the data from the complete years between 1985 and 2005. For each dataset, Figs. 3 and 4 show the time-series respectively for the LW and SW domain. They show the same trends as observed by several authors for the global and tropical means (Zhang et al., 2004; Wong et al., 2006): an increase of the LW fluxes $\left(+5 \mathrm{~W} \mathrm{~m}^{-2}\right)$ and a decrease of the 

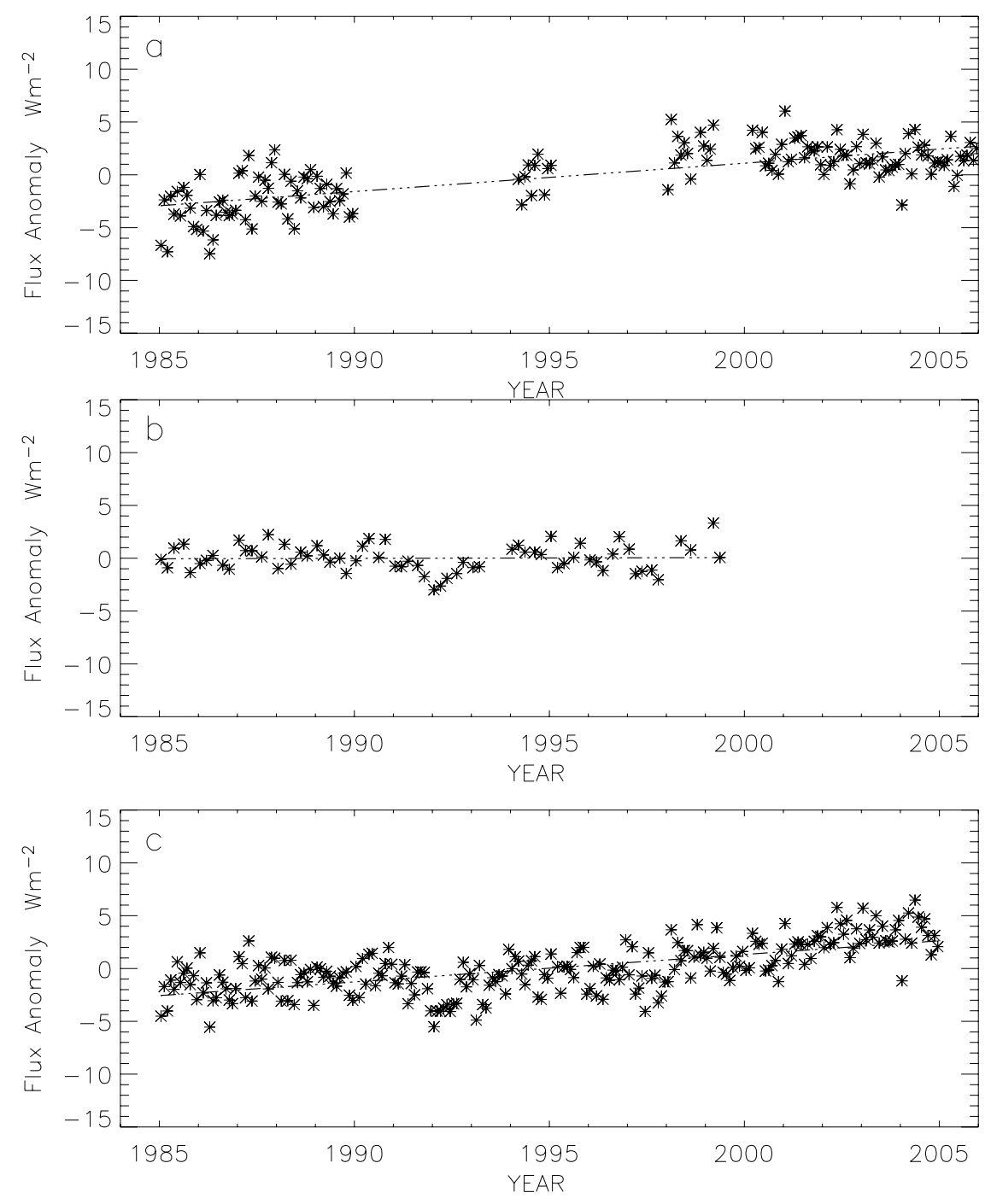

Fig. 3. Evolution of the LW monthly flux anomaly based on the Scanner (a), Nonscanner (b) and ISCCP-FD series (c), averaged over Africa area and the surrounding oceans $\left(45^{\circ} \mathrm{S}-45^{\circ} \mathrm{N} / 60^{\circ} \mathrm{W}-60^{\circ} \mathrm{E}\right)$. Monthly anomalies are defined with respect to all available years. Data versions: Terra FM1 Edition 2 Revision 1 for CERES Scanner, average of the two satellite products (FM1 and FM3) for the common Aqua-Terra period (July 2002 to December 2005), Edition 3 Revision 1 for ERBS Nonscanner, version ii for ISCCP-FD.

$\mathrm{SW}$ fluxes (about $-5 \mathrm{~W} \mathrm{~m}^{-2}$ ) for the 20 years. However, the LW increase is not confirmed by the last version (Edition 3 Revision 1) of the Nonscanner series (Fig. 3b). With the exception of these real or spurious trends, the most striking variations are related to the Pinatubo eruption in 1991 (Minnis et al., 1993). They are observed between 1989 and 1992 showing $\mathrm{SW}$ positive $\left(+5 \mathrm{~W} \mathrm{~m}^{-2}\right)$ and $\mathrm{LW}$ negative anomalies $\left(-4 \mathrm{~W} \mathrm{~m}^{-2}\right)$. On the contrary, the impacts of ENSO are not marked, for example in 1998.

\subsection{Spatial variability of time changes}

Are the trends similar whatever the regions? To answer this question, we have first computed the local anomalies with reference to the whole area. Then we have applied a simple linear least-square regression between regional flux anomalies and year, and plotted (not shown) the geographic distribution of the corresponding slopes and correlation coefficients. We have also computed the differences between two periods (2002-2005 and 1985-1989). The range of variation lies between -2 and $+2 \mathrm{~W} \mathrm{~m}^{-2}$ year $^{-1},-0.8$ to +0.8 and -20 to $+20 \mathrm{~W} \mathrm{~m}^{-2}$, respectively for the slopes, correlation coefficients and period differences. The spatial distributions of these three parameters are similar, so that we only present the maps corresponding to the period differences (Figs. 5 and 6). The same months as on Figs. 1 and 2 (January and August) are selected, although large changes can be observed from one month to another. 

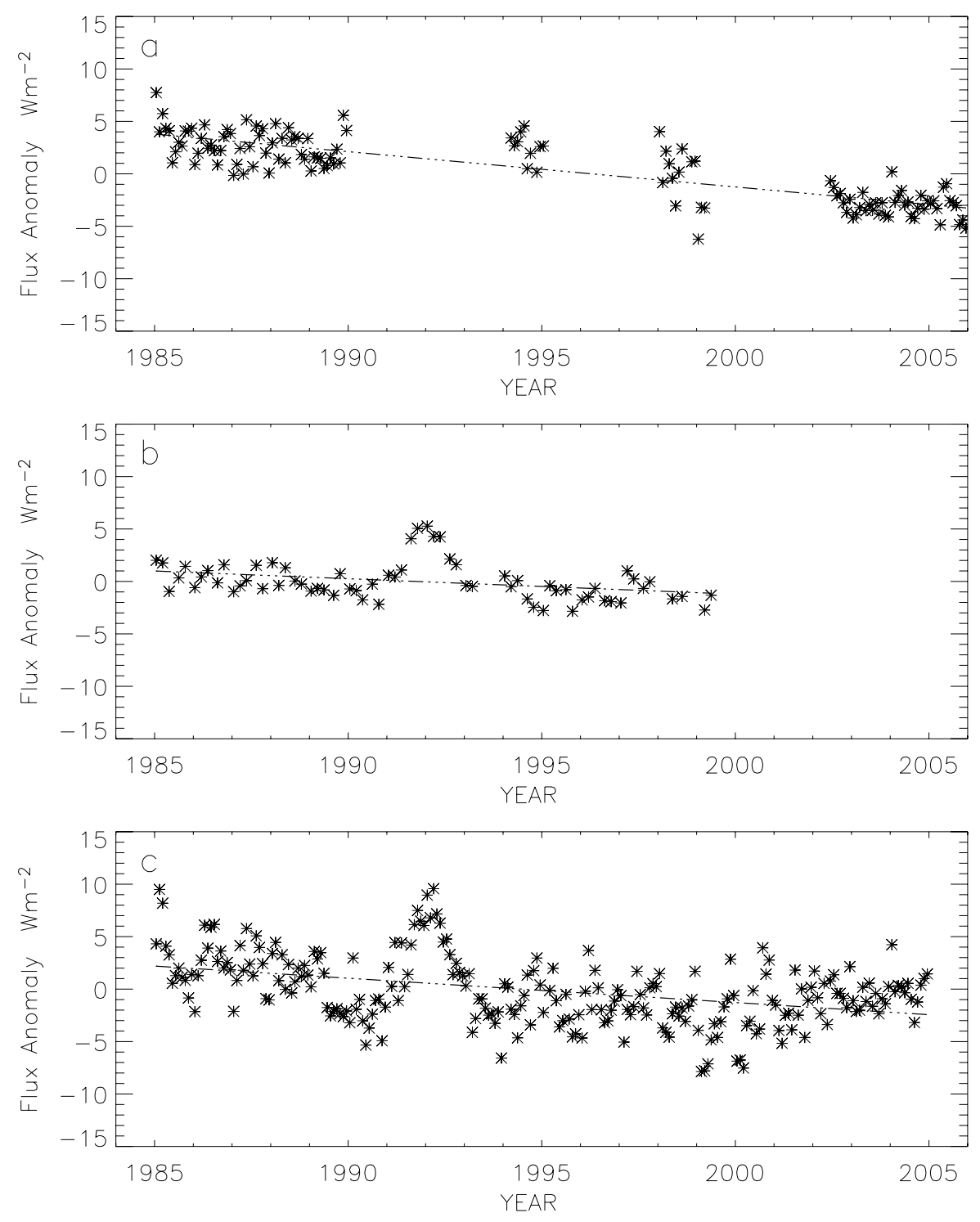

Fig. 4. Same as Fig. 3 but for the SW fluxes.

In the hypothesis that the mean drifts observed on Figs. 3 and 4 are not real, their main impacts have been removed by calculating the local anomalies with reference to the whole area. Yet, regional anomalies can be related to calibration through the scene identification and the choice of the anisotropy correction. However, because the flux is first related to the radiance, this secondary effect is limited if the calibration errors are reasonable. To check this assertion we have simulated these errors by applying the ERBE-like processing to Radiation Budget data (several months of ScaRaB data, Kandel et al., 1998). We change the SW and LW radiances respectively by $2 \%$ and $1 \%$ corresponding to the nominal accuracy of the absolute calibration of the scanner instrument. These modifications impact the scene identification and the instantaneous flux estimate. New monthly regional means are then computed and compared to the original results. In order to be coherent with the method used in the submitted paper, the regional differences are first estimated and then the mean difference over the large area is removed. The worse cases correspond to opposite changes: decrease of SW $(-2 \%)$ and increase of $\mathrm{LW}(+1 \%)$, both concurring to shift the scene identification towards less cloudiness. In this case, simulations were carried out for four months (March, May, September, December 1994) corresponding to different local times of the ascending node (the orbit was slowly precessing). Shown in Table 3, the standard deviations of the regional differences range from 0.57 to $0.81 \mathrm{~W} \mathrm{~m}^{-2}$ (SW) and from 0.23 to $0.27 \mathrm{~W} \mathrm{~m}^{-2}$ (LW), respectively smaller by a factor 10 and 20 compared to the standard deviation of the regional anomalies shown Figs. 5 and 6. In the SW domain, 

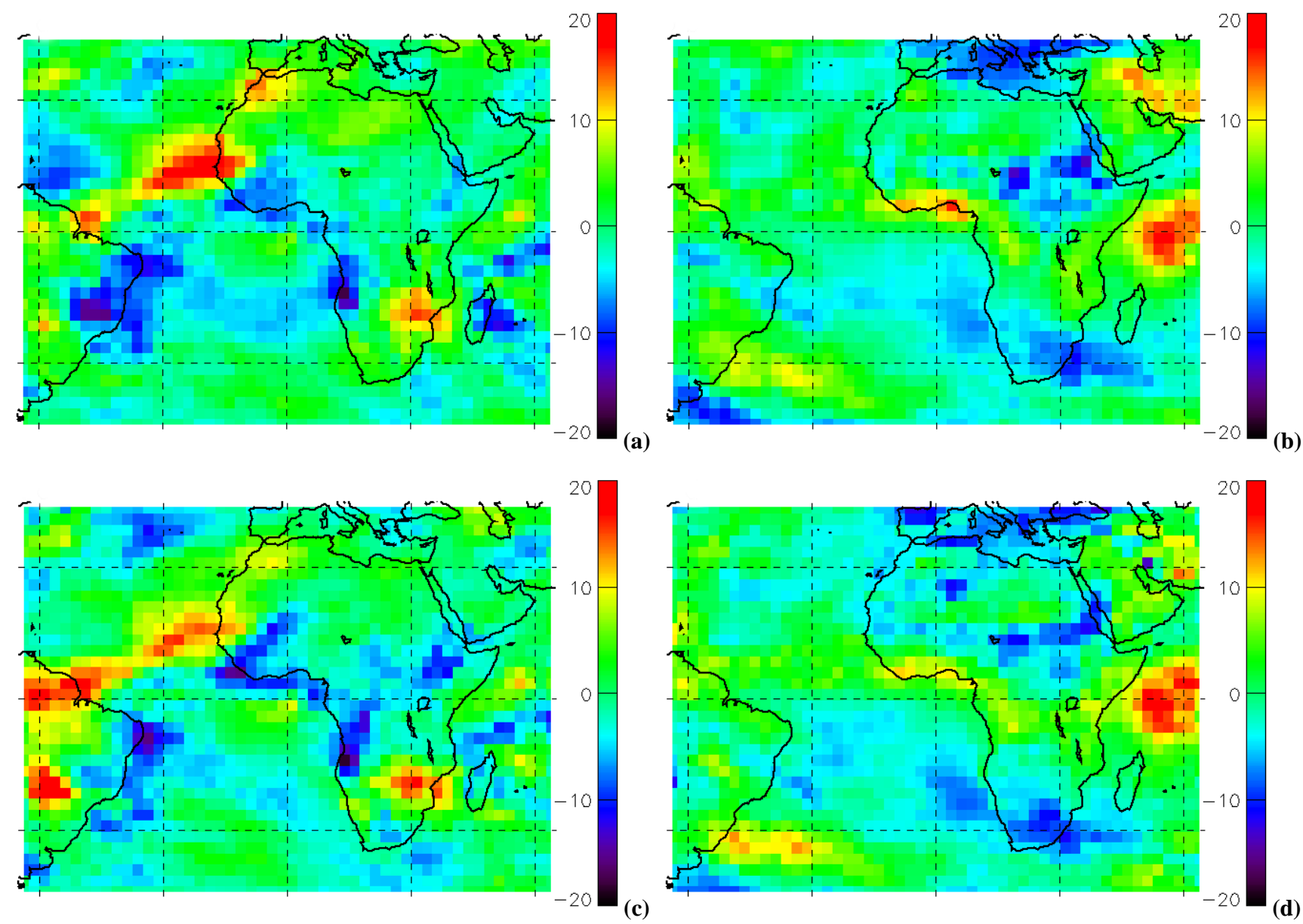

Fig. 5. Temporal change of LW fluxes $\left(\mathrm{W} \mathrm{m}^{-2}\right)$ : 2002-2005 period minus 1985-1989 period, over Africa and surrounding oceans, from Scanner in January (a) and August (b). Corresponding results for ISCCP FD data (c) and (d). The correlation coefficient R between the distributions from the two datasets are 0.79 and 0.83 respectively for January and August.

Table 3. Standard deviation of the regional flux anomalies due to a change in the radiometric calibration: $-2 \%(\mathrm{SW})$ and $+1 \%(\mathrm{LW})$. The simulations correspond to 4 months of ScaRaB. Since the orbit was slowly precessing, each month has different local time of the ascending node (second column). The results must be compared to the standard deviation of 8 and $5 \mathrm{~W} \mathrm{~m}^{-2}$ of the $\mathrm{SW}$ and $\mathrm{LW}$ distributions shown on Figs. 5 and 6: they are smaller by a factor 10 and 20 respectively.

\begin{tabular}{lccc}
\hline \multicolumn{2}{c}{ ScaRaB data 1994 } & \multicolumn{2}{c}{ Standard Deviation of the impact $\left(\mathrm{W} \mathrm{m}^{-2}\right)$} \\
\hline & & SW flux & LW flux \\
\hline March & $22: 00$ & 0.57 & 0.24 \\
May & $15: 00$ & 0.86 & 0.25 \\
September & $01: 30$ & 0.76 & 0.27 \\
December & $15: 15$ & 0.81 & 0.23 \\
\hline
\end{tabular}

Atmos. Chem. Phys., 7, 2617-2629, 2007 these error estimates are maxima, since they are based on only one observation per day. When several observations per day are involved, these errors decrease by compensation effects. We have also studied the case of an extreme calibration drift $(\mathrm{LW}+2 \%, \mathrm{SW}-4 \%)$. In that case, the impact is higher and increases the risk of misinterpretations. For example, it can be confused with a decrease of the net flux over the southern hemisphere. However, even in that extreme case, these errors are significantly smaller than the observed temporal change (by a factor 5 ).

The impact of the calibration on the regional anomalies then is limited and the observed changes (Figs. 5 and 6) most probably are real, specifically if the possible calibration drift is reasonable $(1-2 \%)$ as expected. The spatial patterns for both datasets (Scanner and ISCCP) are remarkably similar specifically for LW (Fig. 5), with correlation coefficients equal to 0.8 and 0.6 respectively for LW and SW domains. For January, the largest $\mathrm{LW}$ increases $\left(+20 \mathrm{~W} \mathrm{~m}^{-2}\right)$ 

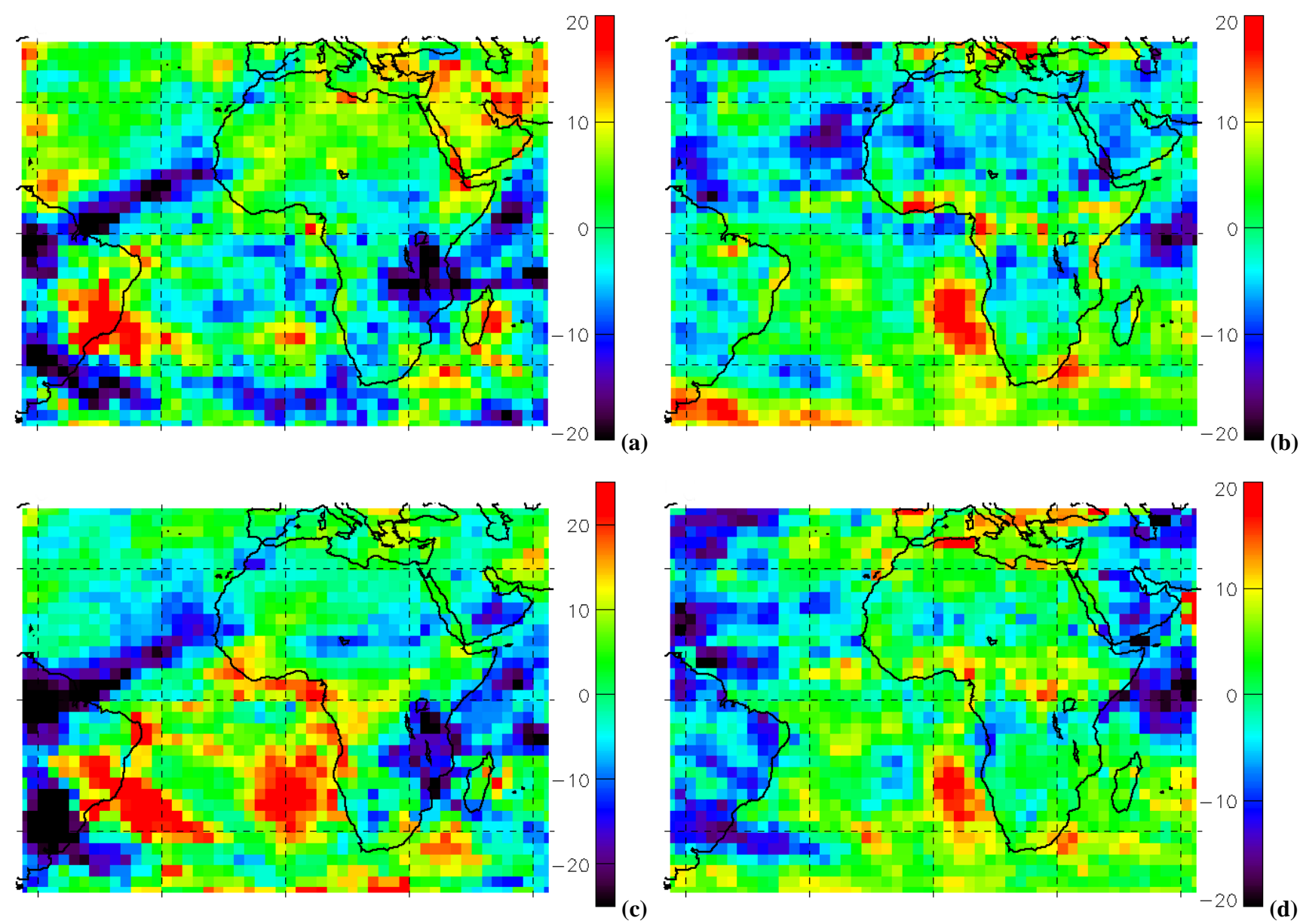

(d)

Fig. 6. Same as Fig. 5 but for the SW fluxes. The correlation coefficients $R$ between the distributions from the two datasets are 0.58 and 0.65 respectively for January and August.

are observed over the South-eastern Africa (around Mozambique) and a long strip crossing the Atlantic from Guyana to Morocco. Negative values $\left(-5\right.$ to $\left.-20 \mathrm{~W} \mathrm{~m}^{-2}\right)$ form a circle surrounding the Gulf of Guinea, composed of the African coasts, of a strip crossing the Atlantic around the Tropic of Capricorn and of the Eastern Brazil. These patterns, but with opposite sign, can also be discerned on the SW maps (Fig. 6), more clearly with ISCCP. On the SW pattern, positive anomalies reach $+20 \mathrm{~W} \mathrm{~m}^{-2}$ over the marine low cloud areas off Angola.

For August, the distributions are totally different. Positive LW trends are observed over a large part of the Indian ocean, around the Persian Gulf, over a small oceanic area off Southern Brazil (around $30^{\circ} \mathrm{S}$ latitude), and over the Guinean Coast. This last feature is not widely extended but clearly appears on both datasets. Slight negative LW trends are observed over Mediterranean area, over the Eastern part of Sahel, over the Southern Africa and the adjacent areas of the Atlantic and Indian Ocean. On the SW maps (Figs. 6b and d), opposite LW trends are observed for some oceanic regions (Indian Ocean, ocean off Southern Brazil and ocean off Southern Africa), but not for the continent. Surprisingly, a few inland parts of the Guinean zone even show both LW and SW positive differences, outlining both warmer and brighter small areas.

Finally, similar distributions of the same two-period differences, but for the yearly means are presented on Figs. 7a $(\mathrm{LW})$ and $7 \mathrm{~b}(\mathrm{SW})$. Due to the yearly averaging calculations, the differences are smoothed and the ranges of variation are smaller than for individual months. In the LW domain, positive variations $\left(7-10 \mathrm{~W} \mathrm{~m}^{-2}\right)$ are observed over the Eastern Brazil. The SW variations range from $-12 \mathrm{~W} \mathrm{~m}^{-2}$ (Brazil) to $15 \mathrm{~W} \mathrm{~m}^{-2}$ (Atlantic, below $35^{\circ}$ ). Positive differences are also observed over Atlantic ITCZ and the marine low clouds off Angola. This information is important since the marine boundary layer clouds are considered as the heart of tropical cloud feedback (Bony and Dufresne, 2005). The robustness of this observation is examined in Fig. 8 which shows that the 

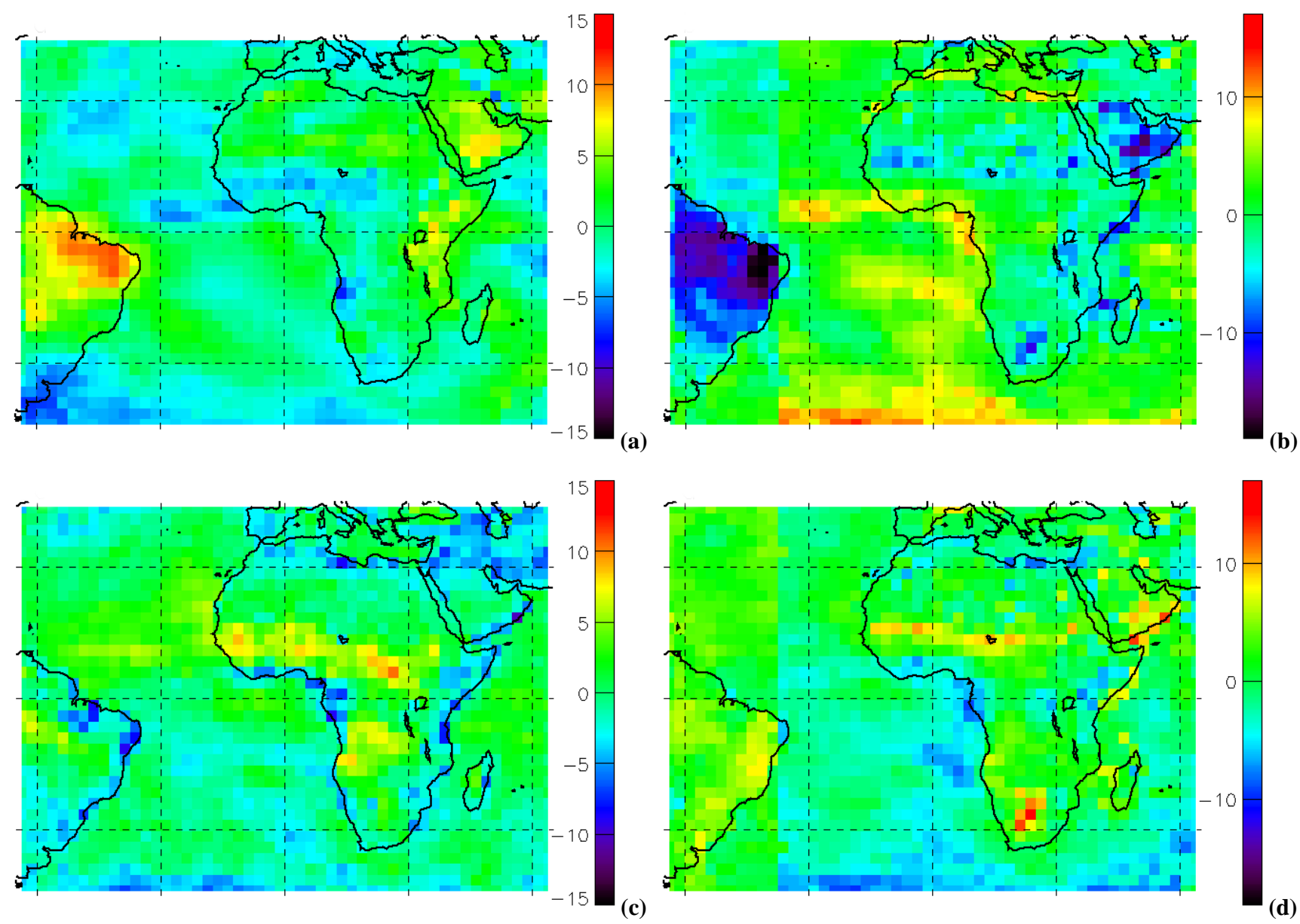

Fig. 7. Temporal change of yearly fluxes $\left(\mathrm{W} \mathrm{m}^{-2}\right.$ ): 2002-2005 period minus 1985-1989 period (all months): LW flux (a), SW flux from the ISCCP-FD data (b), net flux from the scanner series (c), net flux from ISCCP-FD data (d).

SW increase is captured by the three datasets, however, with different uncertainty levels. The slope and 2- $\sigma$ uncertainty of the trends have been calculated according to Weatherhead et al. (1998) by taking into account the variance and autocorrelation in the data. The three slopes are positive. The increase can be estimated to about $2.2,3$ and $6 \mathrm{~W} \mathrm{~m}^{-2}$ respectively for the Scanner, Nonscanner and ISCPP-FD series (extrapolated from 15 years for Nonscanner). However, when taking into account the 2- $\sigma$ uncertainty, only the ISCCP-FD case shows a significant increase (slope $3 \mathrm{~W} \mathrm{~m}^{-2} /$ decade, 2$\sigma=1.6 \mathrm{~W} \mathrm{~m}^{-2} /$ decade).

Since the LW variability is small except over the Eastern Brazil, it is not surprising that the net variations (Fig. 7c Scanners and 7d - ISCCP-FD) reflect the SW variation, but with opposite sign. The artificial discontinuity line at $38^{\circ} \mathrm{W}$ (Fig. 7d) is present in the original SW ISCCP-FD data. Both patterns (from Scanners and ISCCP-FD) are not very similar in details. However a similar decrease (about $-5 \mathrm{~W} \mathrm{~m}^{-2}$ ) is observed over the ocean along the South-western coasts of Africa. Both figures show some similar increases (5 to $7 \mathrm{~W} \mathrm{~m}^{-2}$ ) over the African continent, particularly over the Sahel zone, mainly due to SW decrease. For a better understanding, we have calculated the $10^{\circ} \mathrm{W}$ to $10^{\circ} \mathrm{E}$ flux average as a function of latitude and we have studied each month. The increase of the net radiation is specifically marked for the beginning of the rainy season (April to August). The variation in the Net flux results from different LW and SW variations. For the May monthly mean for example, the Net flux difference reaches about $+10 \mathrm{~W} \mathrm{~m}^{-2}$ around $15^{\circ} \mathrm{N}$. It results from negative differences for both $\mathrm{LW}$ and SW. Observed both with ISCCP-FD and Scanner data, the LW and SW minima occur respectively between 10 and $15^{\circ} \mathrm{N}$ and between 15 and $20^{\circ} \mathrm{N}$. The decrease of the SW flux is not associated with the increase of LW flux suggesting complex variation of low and high clouds and of surface albedo. The explanation could be the surface darkening linked to the positive trend of the vegetation index observed between 1982 and 1999 (Eklundh and Olsson, 2003). 

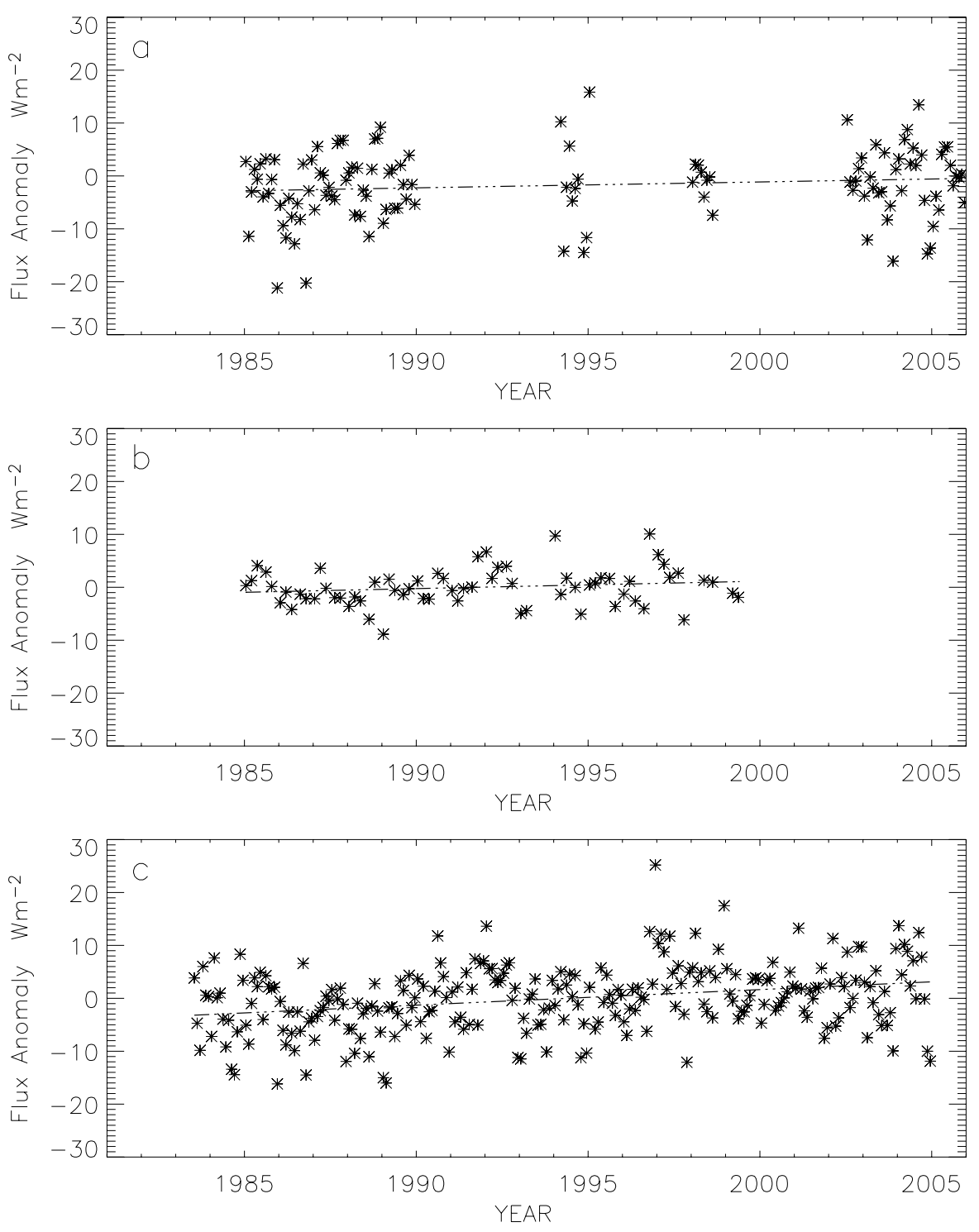

Fig. 8. Differences of the monthly SW flux anomalies between the South East Atlantic $\left(35^{\circ}-10^{\circ} \mathrm{S} / 10^{\circ} \mathrm{W}-10^{\circ} \mathrm{E}\right)$ and the whole studied area, for the three datasets, Scanners (a), Nonscanner (b) and ISCCP-FD (c). Data versions: average of the two satellite products (FM1 and FM3, Edition 2 Revision 1) for the common Aqua-Terra CERES period (July 2002 to December 2005), Edition 3 Revision 1 for ERBS Nonscanner, version ii for ISCCP-FD.

\section{Conclusions}

This study was looking for consistencies between the spatial distributions and temporal changes of radiation budget from three independent datasets over a 20-year period. Indeed, the Scanner series (ERBE, ScaRaB, CERES), the WFOV Nonscanner series and the ISCCP-FD datasets have completely different characteristics: time and space sampling, sensor type, calibration method, flux calculation approach. Intercomparisons are necessary because the uncertainties in each dataset are larger than required. The main uncertainty comes from the radiometric calibration. The uncertainty of
$5 \mathrm{~W} \mathrm{~m}^{-2}$ corresponds to the observed $\mathrm{LW}$ and $\mathrm{SW}$ changes of the mean flux value observed over the large African area under study. It is then difficult to assert that the observed trends are real or linked to an instrument drift. The second problem is the differences in the observation time, which locally introduce biases, over areas with systematic and different diurnal cycles. They are limited for the data we have considered: the ERBS dataset (precessing orbit), the ISCCPFD data (observations each three hours) and the average of the morning and afternoon data for CERES.

In order to make the observations less dependent on the true or spurious observed drifts, we studied spatial 
anomalies, differences between the local flux and the regional mean. Yet, the distribution of these spatial anomalies can also related to calibration through the scene identification and the choice of the anisotropy correction for the flux computation. But the sensibility studies show that the impact of the calibration on the regional anomalies is smaller than the observed change, specifically if the possible calibration drift is reasonable (1-2\%). Large regional changes between 1985-1989 and 2002-2005 periods have been detected, for two selected months (January and August) and for the yearly means. They reveal at least two findings. The first is the increase of the SW flux over a part of the South East Atlantic $\left(35^{\circ}-10^{\circ} \mathrm{S} / 10^{\circ} \mathrm{W}-10^{\circ} \mathrm{E}\right)$, including the marine low cloud area off Angola, found to be equal to 2.2, 3 and $6 \mathrm{Wm}^{-2}$ respectively for the Scanner, Nonscanner and ISCPP-FD series. The second is the increase of the net flux (about $5 \mathrm{Wm}^{-2}$ ) over a narrow strip in the Sahel zone. These two observations should have important links with the evolution of the climate system, since they introduce significant changes of the regional net fluxes. Important LW and SW differences (up to $10 \mathrm{~W} \mathrm{~m}^{-2}$ ) with opposite sign are also observed over the Eastern Brazil. Because of the changes calculated from the Scanner and ISCCP series are highly correlated, we believe that these observations are real. They could be due to the impact of calibration drift, but only if the drifts are significant $(>4 \%)$ and correlated between both datasets, which is highly improbable.

The regional changes of the yearly net flux which have been detected, reach up to $6 \mathrm{~W} \mathrm{~m}^{-2}$ in 20 years, with an uncertainty of $4 \mathrm{~W} \mathrm{~m}^{-2}$ referring to the scatter of the three independent estimates. Changes are still larger when considering the shortwave and longwave fluxes separately, leading to significant changes in the repartition of radiative heat sources and sinks in the atmosphere. This should be linked to variations of other atmospheric and surface parameters, which will be the subject of further investigations. Beyond the regional analysis over Africa and surroundings this study illustrates the difficulty for detecting changes or trends in satellite datasets and emphasizes the need of improved radiometric calibration.

Acknowledgements. The ERBE (S4) and CERES (ES4) data were obtained from the Atmospheric Sciences Data Center at NASA Langley Research Center (http://eosweb.larc.nasa.gov/). The ISCCP FD data were obtained from the International Satellite Cloud Climatology Project web site (http://isccp.giss.nasa.gov) maintained by the ISCCP research group at the NASA Goddard Institute for Space Studies, New York. The most recent version of CERES (Edition 2 Revision 1) was obtained from the GEWEX Radiative Flux Assessment data at the NASA Langley Research Center Atmospheric Science Data Center (http://eosweb.larc.nasa.gov/GEWEX-RFA/). The ScaRaB 1 and 2 experiments were a co-operation between France, Russia and Germany, and their data were obtained at the ClimServ IPSL data centre (http://climserv.ipsl.polytechnique.fr/). This research has been supported by the French National program ACI-Climat.
Edited by: A. Nenes

\section{References}

Allan, R. P., Slingo, A., and Ringer, M. A.: Influence of Dynamics on the Changes in Tropical Cloud Radiative Forcing during the 1998 El Niño, J. Climate, 15, 1979-1986, 2002.

Allan, R. P. and Slingo, A.: Can current climate model forcings explain the spatial and temporal signatures of decadal OLR variations?, Geophys. Res. Lett., 29(7), 1141, doi:10.1029/2001GL014620, 2002.

Barkstrom, B. R.: The Earth Radiation Budget Experiment (ERBE), B. Am. Meteorol. Soc., 65, 1170-1185, 1984.

Barkstrom, B. R., Harrison, E. F., Smith, G. L., Green, R. N., Kibler, J., Cess, R., and the ERBE Science Team: Earth Radiation Budget Experiment (ERBE) Archival of April 1985 Results, B. Am. Meteorol. Soc., 70, 1254-1262, 1989.

Bony, S. and Dufresne, J.: Marine boundary layer clouds at the heart of tropical cloud feedback uncertainties in climate models, Geophys. Res. Lett., 32, L20806, doi:10.1029/2005GL023851, 2005.

Campbell, G. G.: View angle dependence of cloudiness and the trend in ISCCP cloudiness, 13th AMS Conference On Satellite Meteorology And Oceanography, Norfolk, VA, 9/20/20049/23/2004, 2004.

Cess, R. D., Zhang, M., Wielicki, B. A., Young, D. F., Zhou, X., and Nikitenko, Y.: The Influence of the 1998 El Niño upon CloudRadiative Forcing over the Pacific Warm Pool, J. Climate, 14, 2129-2137, 2001.

Eklundh, L. and Olsson, L.: Vegetation index trends for the African Sahel 1982-1999, Geophys. Res. Lett., 30(8), 1430, doi:10.1029/2002GL016772, 2003.

Green, R. N. and Smith, G. L.: Shortwave Shape Factor Inversion of Earth Radiation Budget Observations, J. Atmos. Sci., 48, 390402, 1991.

Haeffelin, M., Wielicki, B. A., Duvel, J. P., Priestley, K., and Viollier, M.: Intercalibration of CERES and ScaRaB Earth radiation budget datasets using temporally and spatially collocated radiance measurements, Geophys. Res. Lett., 28(1), 167-170, 2001.

Harries, J. E., Russell, J. E., Hanafin, J. A., et al.: The Geostationary Earth Radiation Budget Project, Bull. Am. Meteor. Soc., 86(7), 945-960, doi:10.1175/BAMS-86-7-945, 2005.

Hatzidimitriou, D., Vardavas, I., Pavlakis, K. G., Hatzianastassiou, N., Matsoukas, C., and Drakakis, E.: On the decadal increase in the tropical mean outgoing longwave radiation for the period 1984-2000, Atmos. Chem. Phys., 4, 1419-1425, 2004, http://www.atmos-chem-phys.net/4/1419/2004/.

Kandel R., Viollier, M., Raberanto, P., Duvel, J. Ph., Pakhomov, L. A., Golovko, V. A., Trishchenko, A. P., Mueller, J., Raschke, E., Stuhlmann, R., and the International ScaRaB Scientific Working Group (ISSWG).: The ScaRaB Earth Radiation Budget Dataset, B. Am. Meteorol. Soc., 79, 765-783, 1998.

Kandel, R. and Viollier M.: Planetary Radiation Budgets, Space Sci. Rev., 120, 1-26, 2005.

Loeb, N. G., Kato, S., Loukachine, K., and Manalo-Smith, N.: Angular Distribution Models for Top-of-Atmosphere Radiative Flux Estimation from the Clouds and the Earth's Radiant Energy System Instrument on the Terra Satellite. Part I: Methodology, J. At- 
mos. Ocean. Techn., 22, 338-351, doi:.10.1175/JTECH1712.1, 2005.

Matthews, G., Priestley, K. J., Spence, P., Cooper, D., and Walikainen, D.: Compensation for spectral darkening of short wave optics occurring on the Cloud's and the Earth's Radiant Energy System, in Earth Observing Systems, Proceedings of SPIE, 5882, doi:10.1117/12.618972, 2005.

Minnis, P., Harrison, E. F., Stowe, L. L., Gibson, G. G., Denn, F. M., Doelling, D. R., and Smith Jr., W. L.: Radiative Climate Forcing by the Mt. Pinatubo Eruption, Science, 259, 1411-1415, 1993.

Pinker, R. T., Zhang, B., and Dutton, E. G.: Do Satellites Detect Trends in Surface Solar Radiation?, Science, 308, 850-854, 2005.

Rigollier C., Lefèvre M., and Wald L.: The method Heliosat-2 for deriving shortwave solar radiation data from satellite images, Solar Energy, 77(2), 159-169, 2004.

Ringer, M. A.: Interannual variability of the Earth's radiation budget: Some regional studies, Int. J. Clim., 17, 929-951, 1997.

Ringer, R. and Shine, K. P.: Sensitivity of the Earth's radiation budget to interannual variations in cloud amount, Clim. Dynam., 13, 213-222, 1997.

Robertson, F. R. and Lu, H.: How Well Are Recent Climate Variability Signals Resolved By Satellite Radiative Flux Estimates?, 13th AMS Conference On Satellite Meteorology And Oceanography, Norfolk, VA, 9/20/2004-9/23, 2004.

Rossow, W. B. and Schiffer, R. A.: ISCCP cloud data products, B. Am. Meteorol. Soc., 72, 2-20, 1991.

Rossow, W. B. and Schiffer, R. A.: Advances in Understanding Clouds from ISCCP, B. Am. Meteorol. Soc., 80, 2261-2288, 1999.

Smith, G. L., Szewczyk, Z. P., Rutan, D. A., and Lee III, R. B.: Comparison of measurements from satellite radiation budget instruments, J. Geophys. Res., 111, D04101, doi:10.1029/2005JD006307, 2006.
Weatherhead, E. C., Reinsel, G. C., Tiao, G. C., Meng, X.-L., Choi, D., Cheang, W.-K., Keller, T., DeLuisi, J., Wuebbles, D. J., Kerr, J. B., Miller, A. J., Oltmans, S. J., Frederick, J. E.: Factors affecting the detection of trends: Statistical considerations and applications to environmental data, J. Geophys. Res., 103(D14), 17 149-17 162, 1998

Wielicki, B. A., Barkstrom, B. R., Harrison, E. F., Lee III, R. B., Smith, G. L., and Cooper, J. E.: Clouds and the Earth's Radiant Energy System (CERES): An Earth Observing System Experiment, B. Am. Meteorol. Soc., 77, 853-868, 1996.

Wielicki, B. A., Wong T., Allan R. P, et al.: Evidence for Large Decadal Variability in the Tropical Mean Radiative Energy Budget, Science, 295, 841-844, 2002.

Wild, M., Gilgen, H., Roesch, A., et al.: From Dimming to Brightening: Decadal Changes in Solar Radiation at Earths Surface, Science, 308, 847-850, 2005.

Wong, T., Wielicki, B. A., Lee III, R. B., Smith, G. L., and Bush, K. A.: Re-examination of the Observed Decadal Variability of Earth Radiation Budget using Altitude-corrected ERBE/ERBS Nonscanner WFOV data, J. Climate, 19, 4028-4040, 2006.

Young, D. F., Minnis, P., Doelling, D. R., Gibson, G. G., and Wong, T.: Temporal interpolation methods for the Clouds and the Earth's Radiant Energy System (CERES) experiment, J. Clim. Appl. Meteorol., 37, 572-590, 1998.

Zhang, Y., Rossow, W. B., Lacis, A. A., Oinas, V., and Mishchenko, M. I.: Calculation of radiative fluxes from the surface to top of atmosphere based on ISCCP and other global data sets: Refinements of the radiative transfer model and the input data, J. Geophys. Res., 109, D19105, doi:10.1029/2003JD004457, 2004. 